\title{
O ENCONTRO ENTRE A CRUZ E O DRAGÃO: A MISSÃO JESUÍTICA NA CHINA IMPERIAL (1579-1773)
}

\begin{abstract}
Anna Luisa Souza de Almeida ${ }^{1}$
Resumo: No século XVI, os missionários da Companhia de Jesus empreenderam diversas missões para a China, com o objetivo de propagar o catolicismo. Essa missão teve como figura de destaque o missionário italiano Matteo Ricci (1552-1610), que se tornou um dos principais responsáveis pelo desenvolvimento do trabalho dos jesuítas na China e a sua expansão. Por meio dos seus estudos sobre língua e cultura chinesa, Matteo Ricci desenvolveu formulações teóricas para aproximar os conceitos cristãos da ética confuciana. Isso permitiu aos jesuítas adotarem o método de aculturação, o que possibilitou o dialogo entre o cristianismo e a sociedade chinesa. Entretanto, a intensificação de disputas em torno da controvérsia dos ritos chineses, entre outros fatores, contribuíram para o fim do projeto de cristianização da China Imperial, no século XVIII.

Palavras-chaves: jesuítas, confucionismo, cristianismo.

Abstract: In the sixteenth century, the missionaries of the Society of Jesus undertook various missions to China with the aim of spreading Catholicism. This mission had as a prominent figure the Italian missionary Matteo Ricci (1552-1610), who became one of the responsible for the development of the Jesuit work in China and its expansion. Through his studies on Chinese language and culture, Matteo Ricci developed theoretical formulations to bring Christian concepts closer to Confucian ethics. They allowed the Jesuits to adopt the method of acculturation which enabled the dialogue among Christianity and the Chinese society. However, the intensification of disputes over the controversy of the Chinese rites, among other factors, contributed to the end of the project of Christianization of Imperial China in the eighteenth century.
\end{abstract}

Key-words: jesuits; confucianism; christianity.

\section{Os Jesuítas: O início da jornada - da Europa para a China}

A Sociedade de Jesus $^{2}$ foi fundada por Inácio de Loyola junto com outros companheiros em 1534, e a nova ordem religiosa foi aprovada pelo Papa em 1540. Loyola fixou condições bastante rigorosas para aqueles que queriam ingressar na ordem, ${ }^{3}$ por esses motivos nessa época já se destacava a qualidade do recrutamento e da formação, ao mesmo tempo intelectual e espiritual, dos seus membros. Caracterizando a

\footnotetext{
${ }^{1}$ Bacharel em História pela Universidade Federal de Pernambuco. Contato: Rua 07 de Setembro, Boa Vista, Recife -PE, Brasil. E-mail: anna_luisaskf@yahoo.com.br.

${ }^{2}$ A origem da Companhia de Jesus remonta ao ano de 1534, quando Loyola e mais alguns companheiros decidiram organizar uma irmandade. O objetivo inicial do pequeno grupo, que se formou na França, era o de atuar na conversão dos povos considerados pagãos. Para tanto, queriam trabalhar na Palestina, mas se isso não fosse possível, como de fato não foi, estavam dispostos a aceitar qualquer missão determinada pelo Papa. LUIZETTO, Flávio. Reformas Religiosas. $4^{\circ}$ ed. São Paulo: Contexto, 1998, p. 58.

${ }^{3}$ Idem, p. 57.
} 
Ordem com semelhanças militares e inclusive, adotando uma linguagem militar em sua organização. ${ }^{4}$ Os principais meios de atuação da Ordem eram a prática dos Exercícios Espirituais, ${ }^{5} \mathrm{o}$ incentivo à confissão e a freqüente comunhão, tudo isso tendo como alicerce a obediência rigorosa ao preposto geral e a autoridade papal. ${ }^{6}$

A Companhia de Jesus foi uma das mais comprometidas com o pensamento europeu, desde a sua fundação no século XVI. Essa instituição rapidamente se constituiu numa elite próxima das classes dominantes da Europa, por meio da educação dos seus filhos, além de se destacarem como um dos responsáveis por estender a fé católica e a cultura europeia às terras descobertas pelas navegações. ${ }^{7}$ Assim, durante a expansão colonizadora nos séculos posteriores, os jesuítas empreenderiam um papel primordial na difusão do cristianismo com suas missões, nos mais diferentes territórios.

As chamadas expedições de descoberta, unidas às missões católicas tinham a ânsia de expandir o cristianismo com cálculos mercantis e metas político-estratégicas. Tais expedições ocorreram principalmente porque os Estados católicos, como a Espanha e Portugal, estavam simultaneamente interessadas em fundar enormes impérios e terem os direitos de cristianização, ${ }^{8}$ para que, assim, todas as decisões tomadas fossem apenas de responsabilidade dessas monarquias, sem correr o risco da interferência de Roma em seus negócios.

Em 1554, com a retirada da proibição do comércio com os portugueses e, em 1557, com a concessão de Macau, esta se tornou um estabelecimento oficial permanente, mas nunca chegou a adquirir um estatuto de território de soberania portuguesa e a transação de pessoas e bens entre Macau e Guangzhou (Cantão) para o interior era bastante limitada e vigiada de perto pelas autoridades chinesas. Por esse entreposto também o cristianismo se infiltrava por esta estreita passagem, por isso podese dizer que os primeiros missionários que chegaram no século XVI na China vieram no

\footnotetext{
${ }^{4}$ MULLET, Michael. A Contra-Reforma e a Reforma Católica nos Princípios da Idade Moderna Européia. Lisboa: Gradiva, 1984, pp. 35-38.

${ }^{5}$ Livro que dava direções precisas de como disciplinar emoções e pensamentos, evocando imagens especificas, com o objetivo de manter a devoção e disciplina pessoal. FÜLÖP-MILLER, René. Os Santos que abalaram o mundo. $16^{\circ}$ edição, Rio de Janeiro: José Olympio, 2004, pág. 289.

${ }^{6}$ LUIZETTO, Flávio. Reformas Religiosas. Op. cit., p. 57 e ALBERICO, Giuseppe (org.). História dos Concílios Ecumênicos. $2^{\circ}$ ed. São Paulo: Paulus, 1995, p. 331.

7 JIMÉNEZ, José Antonio Cervera. "La Interpretación Ricciana del Confucianismo". In: Estudios de Asia y África, Cidade do México, vol. XXXVII, n. 2, p. 211-212, mayo-agosto. 2002, pp. 211-239. Disponível em: 〈http://www.redalyc.org/pdf/586/58637201.pdf〉. Acessado em: 29/11/2017.

${ }^{8}$ MULLET, Michael. A Contra-Reforma e a Reforma Católica nos Princípios da Idade Moderna Européia. Op. cit., p. 57.
} 
rastro dos portugueses nos primórdios das grandes descobertas marítimas, tendo a sua mentalidade formada pela Reforma e o pensamento científico desenvolvido na Europa. ${ }^{9}$ Com Macau, era considerada como um viveiro dos missionários que tinham por intuito atravessar a China.

\section{A Missão Jesuítica: os Percursores de Matteo Ricci}

Graças ao empenho de Francisco Xavier (1506-1552), conhecido como o apóstolo do Oriente, nasceu a meta de evangelizar o Império Celestial, pois ele foi um dos primeiros a entender a necessidade de empreender uma missão para a China, a fim de se alcançar uma maior influência do catolicismo, não só no Japão como em toda a Ásia.

Xavier foi o primeiro da Sociedade de Jesus a compreender a capacidade dessas inumeráveis pessoas, deste vasto Império, para absorver a verdade do Evangelho. Como também ele foi o primeiro que nutriu a esperança de espalhar a fé, entre eles. ${ }^{10}$

Francisco Xavier alcançou esta compreensão nos anos em que passou no Japão, entre 1549 e 1552, pregando o cristianismo, ${ }^{11}$ onde, ao debater com os monges japoneses, notou a enorme influência chinesa na formação cultural do Japão. Concluiu que para atrair os japoneses era preciso o cristianismo conquistar a China, haja vista que o fato de os cristãos não terem adentrado no território chinês era visto como algo negativo para os nipônicos. "Eles fazem isso o principal ponto contra nós, que se as coisas eram como nós pregamos, como os chineses não sabiam nada sobre". ${ }^{12}$

Também foi no Japão com Francisco Xavier, que começou a tomar corpo o novo método de adaptação da mensagem evangélica à roupagem de culturas asiáticas distantes da tradição européia, metodologia destinada a alcançar expressão suprema na obra do padre Matteo Ricci (1552-1610) na China. Francisco Xavier ensaiou os primeiros passos de uma nova pedagogia calçada no idioma do país, no conhecimento dos costumes, na adoção das túnicas de algodão dos religiosos nativos, na tentativa de

\footnotetext{
${ }^{9}$ GERNET, Jacques. O Mundo Chinês. Volume I, Rio de Janeiro/Lisboa: Edições Cosmo, 1974, p. 421.

${ }^{10}$ RICCI, Matteo. China in the Sixteenth Century: The Journals of Matthew Ricci: 1583-1610. New York: Random House, 1953, p. 117. (Os textos em línguas estrangeiras foram traduzidos pela autora).

${ }^{11}$ Para se aprofundar na trajetória de Francisco Xavier no Japão ler a monografia de ALENCAR, Angélica Louise de Souza Alencar. Encontro de Culturas: O Pensamento Feudal Nipônico e a Atuação da Igreja Reformada no Século Cristão Japonês (1549-1650). Recife, 2006.

${ }^{12}$ COLERIDGE, Henri, S.J. The Life and Letters of St Francis Xavier. London, vol. 2, 1912, p. 300301 Apud SEBES, Joseph. S. J., "The Precursors of Ricci”. RONAN, Charles E.S.J; OH, Bonnie B.C. East Meets West -The Jesuits in China, 1582-1773. Chicago: Loyola University Press, 1988, p. 24.
} 
traduzir conceitos cristãos com a nomenclatura budista, o que o levou a erros cedo retificados.

O apóstolo descobriu que para ser levado a sério nas cortes dos daimyo, tinha que afastar qualquer associação com os bonzos budistas, desprezados pela ignorância e decadência de costumes. Francisco Xavier, então, vestiu-se como os altos letrados. Esse episódio da troca do algodão pela seda foi conhecido como uma das etapas definidoras da evolução dos jesuítas rumo à adoção de novos métodos de proselitismo na Ásia. Francisco Xavier se convenceu então que os futuros missionários deviam ser homens de grande instrução e conduta. ${ }^{13}$

Francisco Xavier decidiu ir à China para estudar e assim, aprender melhor sobre a fonte das crenças japonesas e seus valores morais, além de empreender a conversão do Imperador ao que ele acreditava ser a verdadeira fé e assim aumentar a presença cristã no continente asiático.

(...) este ano de 52, espero ir a China, pelo grande serviço de nosso Deus que pode resultar, tanto para a China como para o Japão, porque, sabendo os japoneses que os chineses recebem a lei de Deus, hão de perder mais depressa a fé que dedicam as suas seitas. Tenho grande esperança de que tanto os chineses como os japoneses, através da Companhia do Nome de Jesus, hão de deixar as suas idolatrias e adorar a Deus e a Jesus Cristo salvador de todas as gentes. ${ }^{14}$

Entretanto esta tarefa se mostrou bastante difícil, pois os primeiros Imperadores Hongwu (1368-1398) e Yongle (1404-1424) da dinastia Ming, após terem derrotado a dinastia dos Yuan formado pelos mongóis, tinham imposto à China um isolamento dos contatos com estrangeiros, com o objetivo de mantê-la a salvo das influências e, principalmente, ataques estrangeiros. Essa política de proteção foi reforçada por causa dos ataques dos wakō que atacavam as costas litorâneas chinesas ${ }^{15}$.

Francisco Xavier, após partir do Japão, chegou a Cochin em 1552, no dia 24 de janeiro. Foi nomeado Provincial das Índias e, mesmo sabendo das dificuldades imposta pelos Ming em penetrar na China, pediu ao vice-rei português da Índia que indicasse um embaixador português para se encontrar com o Imperador, e ele o acompanharia como

\footnotetext{
${ }^{13}$ SEBES, Joseph. S. J., "The Precursors of Ricci". RONAN, Charles E.S.J; OH, Bonnie B. C. East Meets West -The Jesuits in China, 1582-1773. Op. cit., p. 25 e 26.

14 XAVIER, Francisco. Cartas e Escritos de São Francisco Xavier. São Paulo: Edições Loyola, 1996, p. 105.

${ }^{15}$ SEBES, Joseph. S. J. "The Precursors of Ricci”. RONAN, Charles E. S.J; OH, Bonnie B. C. East Meets West. Op. cit.., pp. 25 e 26.
} 
um representante papal. Essa embaixada levaria presentes ao Imperador, negociaria a mudança das leis contra a entrada de estrangeiros no Império e a libertação dos portugueses na prisão de Cantão.

Foi indicado para a tarefa um amigo próximo de Francisco Xavier, o comerciante Diogo Pereira. ${ }^{16}$ Eles partiram de Goa rumo a Malaca em Abril de 1552, levando um carregamento de presentes para o soberano chinês.

Também escrevia V. Alteza como estava determinado a ir a China pela muita disposição que dizem todos que há naquelas partes para acrescentar-se em nossa santa fé.

Eu me parto de Goa, daqui a cinco dias, para Malaca que é caminho da China, para ir desde ali em companhia de Diogo Pereira à corte do rei da China. Levamos um presente mui rico ao rei da China, de muitas e ricas peças que comprou a sua custa Diogo Pereira. (...)

Este presente que V. Alteza lhe envia é tão grande que, se ele o conhecesse o estimaria mais que ser rei tão grande e poderoso como é. Confio em Deus Nosso Senhor que terá piedade de um reino tão grande como este da China, e que só por sua misericórdia se abrirá caminho para as suas criaturas semelhantes adorem o seu Criador (...).

Vamos a China dois padres e um irmão leigo com Diogo Pereira por embaixador para pedir os portugueses que estão cativos e também para assentar as pazes e amizades entre V. Alteza e o rei da China. ${ }^{17}$

Seus planos foram frustrados pelo comandante do porto e da baía de Malaca, Álvaro de Ataíde da Gama que, desejoso do posto de embaixador para $\mathrm{si}^{18}$, impediu o prosseguimento da embaixada confiscando os presentes e retendo Diogo Pereira.

Francisco Xavier não desanimou e decidiu fazer novos planos, para conseguir o seu objetivo.

Primeiro, ele pensou em cultivar ou, se necessário, comprar a amizade de algum mercador chinês que o levaria ilegalmente para a terra firme. $\mathrm{O}$ édito real, correntes ameaçadoras e o encarceramento de estrangeiros que possuíssem terras na China sem permissão oficial (...). Como prisioneiro, ele poderia semear a semente da palavra entre seus companheiros prisioneiros e quando eles fossem soltos, eles a espalhariam entre a população. ${ }^{19}$

Confiante, partiu a bordo do Santa Cruz com o interprete Antônio China em

\footnotetext{
${ }^{16}$ Negociante rico de Goa, que doou cinco mil pardaus, moeda de valor indiana, para comprar os presentes para o Imperador da China nesta embaixada organizada por Francisco Xavier. Em 1557 ajudou nos processos de sua beatificação pelos seus testemunhos. In XAVIER, Francisco. Cartas e Escritos de São Francisco Xavier. Op. cit., p. 111.

${ }^{17}$ XAVIER, Francisco. Cartas e Escritos de São Francisco Xavier. Op. cit., pp. 111 e 112.

${ }^{18}$ BROCKEY, Matthew Liam. Journey to the East: The Jesuit Mission to China, 1579-1724. The Belknap Press of Harvard University Press: Cambridge/London, 2007, p. 28.

${ }^{19}$ RICCI, Matteo. China in the Sixteenth Century. Op. cit., p. 122.
} 
direção a Shangchuan, uma ilha próxima Hong Kong. Ali pôde conversar com alguns mercadores chineses com a ajuda de um chinês convertido Pedro Lopes, e fez um acordo com um deles para que fosse transportado para o continente. Permaneceu na ilha à espera da oportunidade, porém, o comerciante não apareceu e Xavier acabou por perecer doente, em 3 de dezembro de 1552, morrendo sem conseguir conhecer a sua tão sonhada China. ${ }^{20}$

Seu sucessor nesta empreitada foi Melchior Nunes Barreto (1520-1571), o provincial português dos jesuítas na Índia, que conseguiu informações sobre a China por intermédio dos mercadores portugueses de Malaca. Nos relatórios enviados para Companhia de Jesus, na Europa, falou da riqueza das cidades chinesas, consequentemente a intensidade do comércio, a justiça do mandarinato, e a importância do Imperador.

Melchior Nunes Barreto navegou para Cantão em 1555, acompanhando uma embaixada comercial, permaneceu na cidade por dez meses, ao terminarem as negociações foi obrigado pelos mandarins da província a deixá-la. A sorte dos outros religiosos que se seguiram não foi a melhor. Ao todo, foram cerca de 25 jesuítas, 22 franciscanos, 2 agostinianos e 1 dominicano entre os anos de 1552 e 1583, tentando estabelecer uma residência permanente na China. ${ }^{21}$

A situação mudou quando o superior Geral dos Jesuítas apontou em 1573, como o visitador geral das missões da Ásia, Alessandro Valignano (1539-1606) ${ }^{22}$. Este Foi nomeado para reanimar as missões asiáticas e levar recursos humanos adicionais para permitir aos religiosos uma diminuição do trabalho agrícola, para que com isso pudessem se dedicar com maior vigor ao trabalho missionário.

Animado com a possibilidade do trabalho na China, Alessandro Valignano escreveu ao superior da Província da Índia em Goa solicitando o envio para Macau, de uma pessoa qualificada para se dedicar ao estudo do chinês. Em seus escritos, ele mencionou o nome de Michele Ruggieri (1543-1607), que tinha qualidades como

\footnotetext{
${ }^{20}$ SEBES, Joseph. S. J., "The Precursors of Ricci”. RONAN, Charles, E. S,J; OH, Bonnie, B. C. East Meets West. Op. cit., p. 27.

${ }^{21}$ Idem, p. 30.

${ }^{22}$ SPENCE, Jonathan D. O Palácio da Memória de Matteo Ricci - A História de uma Viagem: Da Europa da Contra-Reforma à China da dinastia Ming. São Paulo: Companhia das Letras, p. 57.
} 
"virtude, habilidade e dedicação necessária para tal empreendimento" ${ }^{23}$. Esta atitude de Alessandro Valignano fazia parte da sua política de incentivar os missionários a aprender as línguas locais nas regiões em que estavam trabalhando.

Michele Ruggieri, ao chegar em Macau, em Julho de 1579, recebeu as instruções de Alessandro Valignano para aprender o idioma chinês, e também, especificamente o dialeto falado em Nanquim, pois era o utilizado pela elite letrada, ao invés do cantonense usado pela maior parte da população de Macau e Guangdong. ${ }^{24}$

Ele escreveu para Rodrigo Vincens, o provincial da Índia, a selecionar pelo menos um padre, que ele julgasse ser adequadamente adaptado para a missão em questão, e enviá-lo para Macau o mais rápido possível. (...) Michele Ruggiere, um italiano de Nápoles, foi selecionado para a posição. (...) Ele chegou em Macau em Julho, 1579 , e imediatamente concentrou-se no trabalho esboçado pelo Visitador Geral. A primeira coisa que ele tinha que fazer era aprender o idioma chinês. ${ }^{25}$

Nos três anos seguintes em que viveu em Macau, Michele Ruggieri se dedicou exclusivamente em aprender o idioma chinês. Nesta época também trabalhou na composição de um catecismo em chinês e na tradução em latim de um dos Quatro Livros de Confúcio. Ao aprofundar o método de aculturação iniciado com Francisco Xavier, Valignano nutria esperanças de conseguir abrir as portas do Império Celestial, por meio da língua.

No início de 1580, Michele Ruggieri sentiu-se seguro o suficiente para viajar ao Cantão na companhia de comerciantes portugueses de Macau, e, como seus antecessores, pediu autorização aos mandarins locais, só que desta vez, o fez na língua própria dos mandarins, o que atraiu a atenção das autoridades.

Pela primeira vez foi dada a um jesuíta a permissão de residir na cidade. Suas habilidades em falar sobre as terras além da fronteira chinesa na língua nativa, atraídos pelos relógios e prismas vindos da Europa, chamaram a atenção de altos funcionários, como a do governador da província de Guangdong.

Estes recursos utilizados por Michele Ruggieri não foram deliberados, pois o uso

\footnotetext{
${ }^{23}$ Antonio Monserrate to Everart Mercurian , Goa, 26 October 1579. In WICKI, Josef. Documenta Indica. Vol. 2. Rome, 1948-1988, p. 645. Apud. BROCKEY, Matthew Liam. Journey to the East.. Op. cit., p. 31.

${ }^{24}$ BROCKEY, Matthew Liam. Journey to the East. Op. cit., p. 31.

${ }^{25}$ RICCI, Matteo. China in the Sixteenth Century. Op. cit., p. 131.
} 
da ciência ocidental como instrumento de prestígio e credibilidade para os portadores da mensagem cristã já tinha sido defendido por Francisco Xavier, o primeiro a perceber a importância da ciência como meio de penetração nas sociedades do Extremo Oriente. Ao conquistar a amizade dos mandarins o missionário italiano esperava poder ter o respeito da população ou, pelo menos, não receber represálias das autoridades locais. Como mostrou Matthew Liam Brockey, ao procurar a proteção das autoridades, Michele Ruggieri inaugurou a estratégia de proteção à missão jesuítica a partir dos mandarins e autoridades chinesas que perdurou até o fim da mesma no século XVIII. ${ }^{26}$

Graças ao sucesso de seus métodos, Michele Ruggieri conseguiu fixar sua primeira residência em Zhaoqing, a capital de Guangdong, num antigo templo local em troca de um relógio para o governador da província, em 1582. Também foi autorizada a entrada de dois companheiros jesuítas na China, dois italianos: Francesco Pasio (15541612) e Matteo Ricci (1552-1610). Alessandro Valignano, então, deu ordens para os missionários virem da Índia para Macau, chegando Matteo Ricci na região de Zhaoqing em 7 de Agosto de 1582.

\section{Nos Passos de Matteo Ricci - O longo caminho para Pequim}

Matteo Ricci nasceu em Macerata, Itália, em 6 de outubro 1552, no mesmo ano da morte de Francisco Xavier. Era o primogênito de onze filhos, entrou para a escola jesuíta local com nove anos de idade. Em 1568, foi a Universidade de Roma para estudar direito e se tornou noviço da ordem jesuíta de Roma em 1571. Ao tomar seus primeiros votos, passou um ano em Florença. Retornou a Roma, onde estudou filosofia e matemática sob a supervisão do jesuíta Clavius (1537-1612), com quem manteve uma intensa troca de correspondência na sua estada na China. ${ }^{27}$ Estudou geometria euclidiana, sistema ptolomaico de astronomia, além da feitura de mapas e mecânica, aprendendo ainda a construir astrolábios e relógios.

A cultura pessoal de Matteo Ricci foi absorvida através dos conhecimentos aprendidos no Colégio Jesuíta de Florença - que freqüentou de 1572 a outubro de 1573 e na Faculdade de Artes do Colégio Romano, onde estudou até $1577 .{ }^{28}$ Este currículo

\footnotetext{
${ }^{26}$ BROCKEY, Matthew Liam. Journey to the East. Op. cit., p. 32.

${ }^{27}$ SPENCE, Jonathan D. O Palácio da Memória de Matteo Ricci. Op. cit., pp.158 e 159.

${ }^{28}$ Idem, p. 156.
} 
fazia parte do um rigoroso treinamento na trilogia de estudos clássicos, matemáticos e científicos, acrescentando-se do treinamento com disputas teológicas.

Nessas escolas jesuítas, do século XVI, dava-se ênfase às ciências como maneira de conquistar as elites européias e à nobreza que valorizavam estes estudos. Ao dar destaque para a matemática, se situavam nas fronteiras do conhecimento moderno porque herdavam o impulso do humanismo renascentista.

Em 1577, Matteo Ricci foi aceito nas missões para a Índia através do Padroado português. Dirigiu-se para Portugal para a Universidade de Coimbra para continuar seus estudos de teologia. Partiu de Lisboa para Goa no início de 1578, com uma frota de três navios: S. Gregório, O bom Jesus e S. Luís, com cerca de quatorze jesuítas. Ao chegar a China em 1582, Matteo Ricci começou a aprender chinês, conseguindo-o com rapidez, graças às técnicas de memorização e estudo cuidadoso da formação dos ideogramas individualmente.

Mesmo considerando tarefa difícil, Matteo Ricci estava entusiasmado com os estudos da língua local, como se pode denotar do seguinte excerto:

Recentemente me entreguei ao estudo da língua chinesa e posso assegurar-lhe que é algo completamente diferente do grego ou do alemão. Na língua falada, há tanta ambiguidade que existem muitas palavras que podem significar mais de mil coisas, e muitas vezes a única diferente entre uma palavra e outra forma como você dá uma entonação alta ou baixa, em quatro diferentes tons. Assim, quando (os chineses) falam entre si, escrevem por extenso as palavras que querem dizer, para poderem ter certeza de se entender - pois todas as letras escritas diferem umas das outras. Quanto a essas letras escritas, você acreditaria sem vê-las e usa-as, como fiz. Eles têm tantas letras quantas são as palavras e as coisas, de modo que existem mais de setenta mil delas, cada uma totalmente diferente e complexa. Se você quiser ver exemplos, posso the enviar um dos seus livros, com uma explicação em anexo. ${ }^{29}$

Matteo Ricci e Michele Ruggieri permaneceram em Zhaoqing por seis anos. Nessa mesma época Ruggieri tomou a decisão de que ambos deviam adotar a vestimenta do clero budista para se aproximar melhor da população e dos mandarins. Pensavam, pois, que aquela era a maneira que os religiosos deviam se vestir para serem considerados santos, como se mostra em uma carta que Matteo Ricci escreveu a um amigo de escola: "Quisera que você pudesse me ver como estou agora: tornei-me um

\footnotetext{
${ }^{29}$ As cartas de Matteo Ricci In VENTURI, Pietro Tacchi, S.J. (org.) Opere storiche. vol. 2, Lettere dalla China, Macerata, 1913. p. 27. Apud. SPENCE, Jonathan D. O Palácio da Memória de Matteo Ricci. Op. cit., p. 152.
} 
homem da China. Em nossas vestes, em nossa aparência, em nossa maneira, e em todos os aspectos exteriores, nos fizemos chineses". 30

Eles enxergavam um paralelismo entre as expressões de cunho budista e o modo cristão, dentre elas a opção de celibato dos monges, a escolha de vida simples, a importância dos templos, as torres e o uso de sinos.

Segundo o próprio Michele Ruggieri, o objetivo da missão em seu início era o de aprender os caracteres da melhor forma possível, de uma maneira que se possa ler os livros chineses, e aprender o idioma para melhor explicar o cristianismo ${ }^{31}$ e conquistar os favores dos chineses.

As cartas de Matteo Ricci e Michele Ruggieri, inclusive, mostram como estavam determinados com a estratégia de ganhar a confiança dos burocratas, oferecendo presentes aos chineses, inclusive solicitando ao Papa que mandasse um relicário religioso, uma Bíblia adornada de quatro idiomas para presenteá-la ao Imperador.

Como forma de aprofundar o seu trabalho, o companheiro de Matteo Ricci escreveu a primeira obra ocidental em chinês, o chamado "catecismo" de Michele Ruggiere, publicado em 1584. A origem deste livro de Michele Ruggiere se encontra em um breve texto latino escrito por ele: "Vera et brevis divinarum rerum expositio", que foi adaptada por jovens chineses que serviam de intérpretes dos missionários de Macau. Essa adaptação foi intitulada em chinês: "Siguo Tianhu Shilu"32 (O Verdadeiro Relato do Senhor do Céu). Este catecismo foi considerado obsoleto pelos próprios jesuítas uma década mais tarde, por causa do uso de terminologias budistas.

Em 1584, enquanto morou na próspera cidade de Zaoquing, Matteo Ricci fez um mapa mundi com os nomes dos países escritos em equivalentes fonéticos chineses. $\mathrm{O}$ que chamou a atenção dos habitantes ricos do local. Por causa desse sucesso Matteo Ricci resolveu fazer uma versão mais completa, na qual trabalhou de 1584 a $1602 .{ }^{33}$ Michele Ruggieri e Matteo Ricci explanavam sobre geometria euclidiana para a elite letrada local que os visitava. No fim de 1584, eles fizeram traduções do Pai-Nosso, dos Dez Mandamentos e da Ave-Maria.

\footnotetext{
${ }^{30}$ As cartas de Matteo Ricci. In VENTURI, Pietro Tacchi, S.J. (org.) Opere storiche. Op. cit. p. 72. Apud. SPENCE, Jonathan. D. O Palácio da Memória de Matteo Ricci. Op. cit., p. 130.

${ }^{31}$ BROCKEY, Matthew Liam. Journey to the East. Op. cit., p. 34.

${ }^{32}$ JIMÉNEZ, José Antonio Cervera. “La Interpretación Ricciana del Confucianismo”. Op. cit., pp. 212 e 213.

${ }^{33}$ SPENCE, Jonathan D. O Palácio da Memória de Matteo Ricci. Op. cit., p. 113.
} 
Para obter maior apoio da Santa Sé, Alessandro Valignano enviou Michele Ruggiere para Roma, em 1588, para pedir que fosse designada uma embaixada para o Imperador Wanli (1572-1620), pois a autorização de permanência dada a Michele Ruggiere não foi estendida a outros missionários após sua saída, e os novos funcionários de Zaoquing, que não tinham amizade com os integrantes da Companhia de Jesus, solicitaram que Matteo Ricci, agora o líder da missão, deixasse o território. Para as autoridades chinesas a ligações entre os jesuítas e os portugueses de Macau sempre havia sido motivo de suspeitas de que os jesuítas na verdade eram espiões da Coroa portuguesa. Por fim, a petição não foi cumprida por Roma e Michele Ruggiere não retornou a China.

A solicitação de Matteo Ricci lhe permitiu ficar no nordeste da província de Guandong, em Shaozhou, evitando, graças a sua diplomacia, uma expulsão para Macau. Neste período o estudioso fomentou significantes progressos na fala e na escrita chinesa, as negociações possibilitaram com que Matteo Ricci fizesse um estudo acurado dos membros da elite letrada.

Por causa deste rígido controle por parte do governo Ming, Matteo Ricci entendeu que os jesuítas precisavam garantir uma proteção permanente dos oficiais chineses, pois sem essa garantia os missionários eram obrigados a se mudar todas as vezes que os mandarins favoráveis a sua presença fossem retirados do cargo. Ao compreender a centralização do poder na corte e sua burocracia, Matteo Ricci começou a acalentar o sonho de ir a Cidade Proibida encaminhar um pedido ao imperador Wanli. Ele esperava obter patrocínio oficial da corte e mesmo que não fosse aceito, recorreria aos altos escalões da burocracia. ${ }^{34}$

Ao ter contato com vários intelectuais Matteo Ricci pôde compreender a importância do papel social dos letrados perante o Império e a sociedade chinesa. Em sua visão havia no Império três religiões significativas - a dos letrados confucianos, os budistas e os taoístas. Sendo a religião dos letrados a mais importante. Nesse período, Matteo Ricci começou a apreciar a ética confucionista sobre a família e o Estado. ${ }^{35}$

Obteve a permissão de Alessandro Valignano e de Roma para ir a Nanquim, durante a sua viagem por sugestão de Qu Taisu (1549-1611), um letrado chinês que

\footnotetext{
${ }^{34}$ BROCKEY, Matthew Liam. Journey to the East. Op. cit., p. 42 e 43.

${ }^{35}$ SPENCE, Jonathan. D. O Palácio da Memória de Matteo Ricci. Op. cit., p. 131-133.
} 
mais tarde se converteu ao cristianismo, ${ }^{36}$ Matteo Ricci deixou sua barba e cabelo crescerem e trocou a vestimenta de monges budistas pelo modo dos letrados, o que ocorreu em maio de 1595, quando se mudou de Shaozou para Nanquim. ${ }^{37}$

O objetivo inicial do religioso italiano era o de afastar as associações entre os missionários jesuítas com os monges budistas, pois durante a Dinastia Ming os monges não gozavam de uma alta reputação perante a sociedade e também permitir que os Jesuítas fossem aceitos pelos letrados como eruditos ao modo chinês.

Como a permissão para ficar em Nanquim foi negada, Matteo Ricci instalou-se em Nanchang, na província de Jiangxi entre os anos de 1595 e 1598. Entre meados de 1594 e 1595, Matteo Ricci terminou a tradução para o latim dos Quatro Livros dos clássicos de Confúcio, sendo eles os Analetos, Mêncio, O Grande Ensinamento e o Grande Sentido.

Com isso foi inaugurada a metodologia de "acomodação" do confucianismo. As viagens que foram feitas às diferentes cidades através dos transportes do Grande Canal que era controlado pelos eunucos, força dominante durante o reinado do imperador Wanli - foi importante para estudar o comportamento dos chineses e ter um amadurecimento na metodologia escolhida, com a finalidade de conquistar a confiança dos altos escalões da sociedade, apelando para a sensibilidade moral da elite e o gosto pelo exótico, com as suas habilidades de retórica.

No começo a assimilação do confucionismo e a aliança contra os budistas tinham um objetivo tático, entretanto os seus escritos posteriores mostram que a sua compreensão após estudar e trabalhar na tradução os clássicos confucianos, o levou a se aproximar da doutrina confuciana. Matteo Ricci se sentiu atraído pelo confucianismo, não por seus valores religiosos, mas sim, pela sua natureza não religiosa, seus valores éticos e sociais. Assim convenceu-se da compatibilidade dos ensinamentos do cristianismo com a ética confucianista.

Em 1595, o religioso lançou a tradução de diversos alforismos de Cícero e Sêneca sob o título de "Jiaoyun Lun" (Sobre a Amizade) com a intenção de incentivar o conhecimento sobre os ocidentais para um nobre Ming em Nanchang, obra que lhe trouxe muito prestígio, segundo seus próprios relatos, entre os eruditos chineses. Matteo

\footnotetext{
${ }^{36}$ BROCKEY, Matthew Liam. Journey to the East..Op. cit., p. 43.

${ }^{37}$ JIMÉNEZ, José Antonio Cervera. "La Interpretación Ricciana del Confucianismo”. Op. cit., p. 216.
} 
Ricci pediu ajuda aos seus amigos chineses para colocar em circulação seu livro e outras obras suas. Esta nova política começou a dar frutos muito importantes.

Em Nanchang (1595-1598) se deu a real entrada de Matteo Ricci no convívio social com os letrados confucianistas, graças a sua nova estratégia. Como também pela obra em chinês, por possuir uma memória prodigiosa, e por sua personalidade adquiriu um prestígio sem precedentes. ${ }^{38}$ Em diante, Matteo Ricci passou a se dedicar à impressão, operando em escala maciça dessa obra. Para consolidar o trabalho jesuítico na cidade, chamou João Soeiro e Sebastião Fernandes que estavam em Shaozou, para residirem juntos.

Nessa época que Matteo Ricci fez a sua interpretação sobre o confucianismo. Mais tarde publicou em Pequim "Tianzhu Siyi”, do qual falaremos posteriormente. Graças à fama de erudito, as suas relações pessoais o ajudaram a obter autorização para viajar a cidade de Nanquim, ${ }^{39}$ no verão de 1598.

Também em Nanquim, onde ficou de 1599 a 1601, conheceu os letrados chineses Xu Guangqi (1562-1633), Li Zhizao (1565-1630) e Yang Tingyun (15571627), que eram membros da burocracia e haviam passado nos exames destinados a ocupar os cargos oficiais com $\mathrm{Li}$ e $\mathrm{Xu}$ alcançando um dos mais altos níveis do serviço civil, sendo $\mathrm{Xu}$ parte do grande secretariado Imperial. ${ }^{40} \mathrm{Com}$ estes amigos influentes começou uma longa e exaustiva rotina de jantares nas casas dos altos funcionários, onde encontrava o clero budista da região e seguiam longos debates, porém com cautela devido ao receio de perder a confiança dos letrados confucianistas. ${ }^{41}$

Em seguida, veio a Pequim em Janeiro de 1601, na companhia de oito jesuítas, essa viagem só foi possível por causa do sucesso alcançado pelos padres nas missões nas províncias chinesas. Como Matteo Ricci enviou alguns presentes que encantaram o Imperador Wanli, este ficou curioso e ordenou que fossem feitos retratos dos jesuítas para que ele pudesse conhecê-los.

Logo, Matteo Ricci e seu companheiro missionário Diego de Pantoja (15711618), que acabara de chegar de Macau, fixaram residência na capital Imperial. Em

\footnotetext{
${ }^{38}$ SPENCE, Jonathan D. O Palácio da Memória de Matteo Ricci. Op. cit., p. 27 e JIMÉNEZ, José Antonio Cervera. "La Interpretación Ricciana del Confucianismo". Op. cit., p. 217.

${ }^{39}$ SPENCE, Jonathan D. $O$ Palácio da Memória de Matteo Ricci. Op. cit., p. 97.

${ }^{40}$ BROCKEY, Matthew Liam. Journey to the East. Op. cit., p. 58 e 59.

${ }^{41}$ SPENCE, Jonathan D. O Palácio da Memória de Matteo Ricci. Op. cit., p. 175.
} 
1602, Matteo Ricci pôde se curvar diante do trono vazio do dragão (vazio porque Wanli não recebia visitas cerimoniais), esta honraria foi obtida também porque, além dos mandarins, ao chegar a capital, Matteo Ricci empenhou-se em ganhar a simpatia dos eunucos, que dominavam a vida na Cidade Proibida na era Wanli.

Com Jesuítas residindo em Pequim a reputação dos missionários melhorou entre os chineses. Assim que as notícias da recepção de Matteo Ricci na Capital se espalharam, o destino dos religiosos da Companhia de Jesus nas províncias de Nanjing, Nanchang e Shaozou melhoraram. Desta forma, a fama alcançada pelos jesuítas foi essencial para garantir a consolidação das missões em outras províncias.

Em 1603, Matteo Ricci lançou o seu catecismo "O Verdadeiro Significado do Senhor do Céu" (Tianzhu shiyi), em que eliminou os termos budistas e adotou como estilo a discussão filosófica com base confuciana. Em 1596, o manuscrito do "catecismo" de Matteo Ricci estava feito, sendo revisado pelas autoridades eclesiásticas. ${ }^{42}$ Matteo Ricci falou sobre a publicação da obra:

E enquanto se fazia uma declaração mais copiosa desta nova Doutrina Cristã, imprimiu o Padre o "Catecismo" (Tianzhu Shiyi), que já havia posto em ordem desde muitos anos, e que todos os nossos usavam escrito à mão. Este não trata de todos os mistérios de nossa Santa Fé, que só se hão de declarar a catecúmenos e cristãos, senão só de alguns principais, especialmente aqueles que de qualquer modo se podem provar com razões naturais e entender com a própria luz natural; assim poderá servir aos cristãos e aos gentiles e poderá ser entendido em outras partes remotas, onde não poderiam chegar tão rápido os nossos, abrindo com isto o caminho aos outros mistérios que dependem da Fé e ciência revelada. Que dizer: que existe no universo um Senhor e Criador de todas as coisas que continuamente as conserva; que a alma do homem é imortal, e que se lhe dá ao pago das boas e das más obras na outra vida de Deus; que é falsa a transmigração das almas em corpos de outros homens e animais, e muitas que seguem, com outras coisas similares. E tudo isto é provado não só com muitas razões e argumentos de nossos santos doutore, mas também com muita autoridade de seus livros antigos, os quais o Padre havia anotado quando os lia; ao qual deu grande autoridade e crédito a esta obra. ${ }^{43}$

$\mathrm{Na}$ obra retratou o cristianismo e o confucianismo como complementos, e criticou os conceitos do "não ser" taoísta $(w u)$ e do "vazio" budista (kong) e se dão razões para igualar os términos tradicionais confucianistas para designar a Deus, Tian

\footnotetext{
${ }^{42}$ BROCKEY, Matthew Liam. Journey to the East: The Jesuit Mission to China, 1579-1724. Op. Cit., p. 47.

${ }^{43}$ RICCI. Matteo. Fonti Ricciane. Storia dell'introzione del Cristianesimo in Cina (textos y cartas originales de Matteo Ricci), vol. 2, Roma, 1949. pp. 291-295. Apud. JIMÉNEZ, José Antonio Cervero. "La Interpretación Ricciana del Confucianismo". Op. cit. pp. 224-225.
} 
(Céu) e Shangdi (O Senhor do Alto), com Tianzhu (O Senhor do Céu).

Aproveitando-se da repercussão da obra, lançou em 1604 “Ershiwu yan” (“Os Vinte e Cinco Preceitos") e em 1608 “Jiren shipian” ("Dez Episódios de um Homem Invulgar”), bem como o livro "Qike” em 1604 (“As Sete Vitórias", ou "Sete Coisas Mortais") que se tornaram populares entre os letratos chineses que contataram com os jesuítas.

Muitos letrados impressionados com as obra de Matteo Ricci e com o seu conhecimento científico resolveram adotar o cristianismo como religião. Os principais foram Xu Guangqi (1562-1633), Li Zhizao (1565-1630) e Yang Tingyun (1557-1627) considerados os pilares do cristianismo chinês. Houve conversão dos burocratas Li Zhizao, que ajudou Matteo Ricci no estudo da cartografia, tornando-se cristão em 1610 e adotando o nome de Leão, ${ }^{44}$ enquanto os outros adotaram os nomes, respectivamente, Paulo e Miguel após a conversão. Da data de suas conversões até o ano de suas mortes estes homens foram verdadeiros protetores e patronos da missão jesuíta, esse patrocínio possibilitou uma maior tranquilidade para os cristãos no prosseguimento da missão. Os últimos anos da vida de Ricci em Pequim foram frutíferos. Contudo, veio a falecer em 10 de maio de $1610,{ }^{45}$ vitimado por exaustão.

\section{Contenda Missionária na China: Instauração de uma Controvérsia.}

Após a morte de Matteo Ricci, os jesuítas em Pequim tornaram-se úteis ao Imperador que, apesar da feroz oposição e de breves períodos de perseguição, conseguiram consolidar a sua missão. Foi permitida a construção de igrejas em várias cidades e a obra espalhou-se gradualmente pelas províncias.

Uma atitude mais conciliatória por parte das autoridades chinesas nas últimas décadas do século XVI, facilitou o estabelecimento de missões franciscanas e dominicanas em diversas cidades do sul da China, a partir de 1632, mas os seus métodos missionários provaram muitas vezes ser de grande embaraço para os seus correligionários jesuítas. As maneiras rudes, os costumes estranhos e a atitude intolerante para com as crenças nativas de muitos desses missionários aumentou a

\footnotetext{
${ }^{44}$ SPENCE, Jonathan D. O Palácio da Memória de Matteo Ricci. Op. cit., p. 168.

${ }^{45}$ Idem, pp. 174-175.
} 
disputas entre as ordens religiosas na $\mathrm{China}^{46}$, principalmente a questão da metodologia empregada pelos jesuítas na acomodação à cultura chinesa, que incluía aceitação dos ritos chineses como não sendo heréticos, por não possuírem caráter religioso e sim, civil. $^{47}$

Após 1610, a oposição ao projeto missionário acomodacionista não se fez esperar, e com a chegada dos dominicanos e franciscanos os missionários jesuítas iniciaram uma querela que haveria de durar muitos anos, transformando-se numa controvérsia sobre os ritos chineses que, no século XVIII acabou por ser resolvida com a eliminação da accommodatio.

Os Ritos Chineses, aos quais os religiosos se referiam, eram o culto oficial a Confúcio e aos antepassados que também faziam parte do confucianismo. Confúcio tinha sido adorado principalmente pelos mandarins e esse culto parecia ter tido início nas escolas. $\mathrm{O}$ ato de cultuar fundamentava-se na idéia de que, tal como uma família sacrifica e ora aos espíritos dos seus antepassados, e tal como cada comércio ou grêmio presta reverência anual ao seu deus patrono, assim deveria proceder a classe escolar, que deveria realizar atos regulares de culto nos templos erigidos à memória de Confúcio, que era o centro de toda a cultura e saber chineses. Prestava-se reverência a Confúcio como grande mestre, por isso também era prestada reverência aos seus discípulos e a todos os grandes do passado cujos ensinamentos haviam contribuído notavelmente para a cultura e moralidade.

Não havia culto a Confúcio a não ser pelos membros de sua própria família antes do tempo da dinastia Han, Kaotzu (195 a.C.). O primeiro exemplo de culto a Confúcio nas escolas foi um decreto feito pelo imperador Ming (59), pelo qual Confúcio se tornou o patrono deificado dos escolares, ordenando-se que se lhe oferecessem sacrifícios.

A contenda entre os jesuítas foi iniciada por missionários jesuítas como Niccolò Langobardo (1565-1655), sucessor de Matteo Ricci como superior da missão na China que começou a evangelizar o povo, em vez dos cultos letrados. Para Niccolò Langobardo:

(...) os antigos sábios eram ateus como os modernos confucianistas e

\footnotetext{
${ }^{46}$ Idem, p. 69.

${ }^{47}$ SEBES, Joseph. S. J. “The Precursors of Ricci”. Op. cit .p. 48- 49.
} 
os ritos a Confúcio e aos antepassados eram superstições condenáveis. Estas idéias seguiram a alguns jesuítas e quase todos os dominicanos e franciscanos que chegaram posteriormente à missão. Este foi o núcleo da controvérsia dos ritos chineses. ${ }^{48}$

Outro debate era sobre os termos chineses utilizados para significar Deus. Jesuítas como João Rodrigues (1561-1633) faziam objeções a maneira como Matteo Ricci e seus companheiros fizeram uso das terminologias cristãs provenientes dos conceitos confucianos. Os termos polêmicos eram: Tian (Céu), Shangdi (Senhor do Alto), Tianzhu (Senhor do Céu). A principal preocupação entre os missionários era de que as terminologias poderiam causar ambiguidade entre os conversos chineses sobre a verdadeira natureza do Deus cristão. Por causa da proporção das discussões o Visitador André Palmeiro (1569-1635) decidiu que o termo Tianzhu seria o utilizado para nominar Deus e, os outros deviam ser banidos dos escritos jesuíticos.

No início do século XVII, havia missionários jesuítas distribuídos por quatro grandes áreas de residência: Nanquim, Pequim, Nanchang, Shaozhou, provendo as necessidades espirituais dos conversos.

Daí em diante, os jesuítas continuaram a exercer a sua influência sobre o imperador e os letrados, porém mais pelos progressos mecânicos, métodos científicos e atividades artísticas dos europeus - música e principalmente a pintura, do que pelo ensinamento da doutrina cristã. E com a chegada à China de novos missionários como Johann Adam Schall von Bell, Giacomo Rho, Johan Terrenz Schreck e, mais tarde, Ferdinand Verbiest houve reforço no empenho dos jesuítas junto da corte de Pequim.

Assim, enquanto os jesuítas trabalhavam nas suas missões, outras ordens mendicantes vindas de Manila estabeleceram as suas missões em Fujian. O dominicano Juan Baptista de Morales e o franciscano Antonio de Caballero logo se envolveram numa controvérsia com os jesuítas sobre a questão dos ritos e cerimônias ancestrais.

A partir de 1632, a querela missionária deu razão a uma série de perseguições e a uma crescente reação anticristã por parte dos chineses.

Com a proclamação da nova dinastia Qing (1644-1911), em Pequim, os jesuítas não mudaram a sua estratégia de proteção da missão católica. A diferença era que os

\footnotetext{
48 JIMÉNEZ, José Antonio Cervera. “La Interpretación Ricciana del Confucianismo”. Op. cit., p. 237.
} 
jesuítas tinham mais uma vez em estabelecer sua legitimidade diante dos novos soberanos e, assim, garantir a sua segurança política.

Enquanto se estava lutando pela soberania do Império, os jesuítas adotaram a política de se manterem leais a quem estivesse no poder. Enquanto que em Pequim, Johann Adam Schall Von Bell (1592-1666) ofereceu as suas habilidades científicas aos governantes Manchus. Os jesuítas que estavam ao sul da China tornaram-se aliados do Príncipe de Fu, neto de Wanli (dinastia Ming), que durante um curto período de tempo foi nomeado "Imperador" na cidade de Nanquim.

Quando estava na Corte, Johann Adam Schall Von Bell entendeu a necessidade dos novos soberanos em legitimar o seu regime e, por isso lhes apresentou uma versão do calendário chinês. Com esse gesto, conseguiu ser nomeado como diretor do Conselho Imperial de astronomia pelo regente Dorgon, o que o tornou, também, próximo do Imperador Sunzhi (1638-1661) que chamava o jesuíta de "mafa" (vovô), e permitiu que construísse uma Igreja na capital. ${ }^{49}$ Com a morte de Sunzhi, o missionário foi preso, acusado de ter colaborado com a morte do Imperador, tendo a pena anulada em 1655, acabando por falecer em 1666, devidos aos maus-tratos na prisão.

Com isso a convivência dos jesuítas na corte ficou difícil pois eles começaram a ser duramente criticados pelos astrônomos muçulmanos e chineses que diziam que os cálculos feitos pelos religiosos estavam errados. Essa contenda só teve fim quando o Imperador Kangxi (1654-1722) assumiu o trono em 1667, por sua alta cultura, conhecimentos trazidos do Ocidente pelos missionários, apresentando-se como um monarca favorável à presença dos jesuítas na corte. Proclamou a aceitação oficial do cristianismo no Édito de Tolerância do imperador Kangxi, em 1692, pelo qual a religião católica e seus religiosos receberam proteção liberdades oficiais.

E o outro Édito 'Declaração relativa ao significado dos ritos ou costumes chineses segundo o qual a Companhia de Jesus os tem até agora permitido, oferecida ao imperador Kangxi, em 30 de novembro do ano do Senhor de 1700'. Quem desempenhou um importante papel na feitura deste segundo Édito foi o jesuíta português Tomás Pereira (1645-1708) que já havia cooperado com o monarca no tratado de paz de Nerchinsk, assinado em 1685 com a Rússia, junto com o Jesuíta Jean-

\footnotetext{
${ }^{49}$ BROCKEY, Matthew Liam. Journey to the East. Op. cit., p. 110. e SPENCE, Jonathan D. Em Busca da China Moderna (Quatro Séculos de História). São Paulo: Companhia das Letras, 2002, pp. 60 e 61.
} 
François Gerbillon. Sendo ele o escolhido para ler o texto de agradecimento ao Imperador por tão importante decreto:

Era este o nosso único desejo, a só esperança que nos ia sustentando e o termo a que se encaminhavam dia e noite os nossos pensamentos e aspirações: chegar ao felicíssimo momento em que, por graça de V. Magestade, nos fosse outorgada a liberdade de pregar publicamente neste vasto Império o culto do verdadeiro Deus.Por esse motivo, bem o sabe V. Magestade, deixamos nossas famílias e nossas pátrias e viemos através de tantos perigos colocar-nos a serviço de V. magestade. Já nos tinha cumulado de favor sem conto, mas a graça que hoje nos faz, escede-os a todos e lhes vem por o remate. Por ela nunca nós poderemos testemunhar a V. Magestade, como desejávamos, o justo reconhecimento de que transbordam os nossos corações. $^{50}$

A controvérsia sobre os Ritos Chineses acentuou-se na China e em Roma, desde meados do século XVII e, em 1645, o Papa condenou a metodologia de evangelização jesuítica, depois de ter ponderado as acusações de frei Juan Morales, enviado a Roma para interceder pela causa dominicana. Quando Martino Martini veio apresentar o ponto de vista jesuíta - que estes ritos constituíam um culto meramente cívico e social - o Papa Alexandre VII decidiu aprovar o método de acomodação em 1656. Até o século XVIII, ambas as partes produziram tratados cheios de denúncias mútuas.

O Frei Domingo Fernandez Navarrete publicou críticas contundentes aos métodos jesuítas na China no "Tratados sobre História”, "Política, Ética e Religião da Monarquia Chinesa" (1676).

No Verão de 1706, foi lançado um decreto imperial que expulsava da China todos os missionários que se recusassem a jurar conservar as leis antigas ditadas por Matteo Ricci relativas aos Ritos chineses. Embora tentativas sinceras de reconciliação fossem feitas.

Após muitas contradições, os ritos foram condenados como idolatria pela constituição Ex illa die, publicada em Roma em 1715. O então tolerante imperador ameaçou banir o cristianismo ao tomar conhecimento do documento. Kangxi escreveu o seguinte comentário à margem de cópia da tradução em chinês da Ex illa die, pois com a promulgação da bula papal o imperador se sentiu desrespeitado:

\footnotetext{
${ }^{50}$ RAMOS, João de Deus. História das Relações Diplomáticas entre Portugal e China - O Padre António de Magalhães, S. J., e a Embaixada de Kangxi a D. João V (1721-1725). Macau: Instituto Cultural de Macau, 1991, p. 44 e RODRIGUES, Francisco. Jesuítas Portugueses - Astrônomos na China. Macau: Instituto Cultural de Macau, 1990, p. 16.
} 
Depois de ler este decreto, só posso dizer que os europeus são um povo de mentalidade tacanha. Como podem falar dos princípios morais chineses quando nada sabem dos costumes, livros ou língua da China que lhes capacitassem a entendê-los? Muito do que dizem ou discutem nos fazem rir. Vi hoje o Legado do Papa (Mezzabarba) e o decreto. Ele é como um ignorante sacerdote budista ou taoísta, ao passo que as superstições mencionadas são aquelas de religiões sem importância. Esse tipo de palavrório violento não poderia ser mais extremado. A partir de agora, os europeus não deveriam mais pregar na China. Tem de ser proibido a fim de evitar perturbações. ${ }^{51}$

Os missionários passaram a trabalhar com dificuldades cada vez maiores, sujeitos a perseguições intermitentes e praticamente concentrados nas classes mais pobres, pois a posterior e final condenação dos ritos, em 1742, tornou quase impossível a conversão de funcionários e letrados.

O imperador Yungcheng (1678-1735), que subiu ao trono em 1723, não encarava os jesuítas com tanta admiração como o seu pai. Ao discutir com os missionários em Pequim exprimiu com aguda presciência o perigo da chamada "diplomacia das canhoneiras" ${ }^{52}$ que se concretizaria no século XIX.

Dizem que a vossa lei não é falsa. Acredito em vós. Se imaginasse que era falsa, o que me impediria de destruir as vossas igrejas e de vos expulsar delas?

Que diria se eu mandasse um grupo de bonzos e lamas ao vosso país para pregar as doutrinas dele? Quereis que todos os chineses se tornem cristãos. Sei que a vossa lei exige. Mas nesse caso, o que é que nos acontecerá? Tornar-nos-emos súditos do vosso rei? Os convertidos que fazeis reconhecerão somente a vós em tempos de perturbações.

Eles não escutarão nenhuma outra voz, a não ser a vossa. Sei que, no momento atual, nada há a temer, mas quando vossos navios começarem a chegar aos milhares, haverá provavelmente grande desordem (....) (O imperador K'ang-hsi), meu pai, perdeu boa parte de sua reputação junto aos letrados devido à condescendência com que permitiu que vos estabelecêsseis aqui. As leis de nossos antigos sábios não permitirão mudanças, e eu não permitirei que meu reinado seja objeto de tal acusação. ${ }^{53}$

Em Janeiro de 1724 foi publicado o decreto de expulsão dos missionários que abrangia todos os missionários menos os que estavam em Pequim. Os missionários primeiramente, foram expulsos para Cantão, e mais tarde para Macau. As igrejas em

\footnotetext{
${ }^{51}$ BOXER, Charles. O Império Marítimo Português 1415-1825. São Paulo: Companhia das Letras, 2002 , p. 254.

${ }_{52}^{5}$ Idem, p. 256.

${ }^{53}$ Ibidem.
} 
todas as províncias foram profanadas ou destruídas ${ }^{54}$. Só as igrejas de Pequim se conservavam abertas. Apesar da repressão, numerosos padres, com o risco das próprias vidas, prosseguiram no trabalho de evangelização circulando secretamente de lugar para lugar e escondendo-se geralmente em barcas. Em 1746 intensificou-se a perseguição, até que, em 1773, quando da supressão da ordem dos jesuítas deu-se por encerrada a missão de evangelização dos jesuítas na China.

\section{Referências Bibliográficas}

ADLER. Joseph A. Religiões da China. Portugal: Edições 70, 2002.

ALBERICO, Giuseppe (org.). História dos Concílios Ecumênicos. 2a ed. São Paulo: Paulus, 1995.

BOXER, Charles. O Império Marítimo Português 1415-1825. São Paulo: Companhia das Letras, 2002.

BRAZÃO, Eduardo. Apontamentos para a História das Relações Diplomáticas de Portugal com a China (1516-1753). Lisboa: Agência Geral das Colônias, 1949.

BROCKEY, Liam Matthew. Journey to the East: The Jesuit Mission to China, 1579-1724. Cambridge/Massachusetts/London/England: The Belknap Press of Harvard University Press, 2007.

BURCKHARDT, Titus. A Arte Sagrada - No Oriente e no Ocidente. São Paulo: Attar, 2004.

CARMO, António. A Longa Marcha das Religiões na China. Macau: Fundação Macau, 1994.

Igreja Católica na China no Contexto do Sudeste Asiático. Que Futuro? Macau: Fundação Macau, Instituto Cultural de Macau, Instituto Português do Oriente, 1994.

CHANG, Tien-Tsê. O Comércio Sino-Português entre 1514 e 1644. Uma Síntese de Fontes Portuguesas e Chinesas. Instituto Português do Oriente, 1995.

CONFÚCIO. Os Analectos. Rio Grande do Sul: L\&P Editores, 2006.

DELUMEAU, Jean. El Catolicismo de Lutero a Voltaire. Barcelona: Editora Labor, 1973.

DRÉGE, Jean Pierre. Marco Pólo e a Rota da Seda. Rio de Janeiro: Objetiva, 2002.

FRANGIOTTI, Roque. História das Heresias (Séculos I-VII): Conflitos Ideológicos dentro do Cristianismo. 2 ed., São Paulo: Editora Paulus, 1997.

FRANKE, Herbert e TRAUZETTEL, Rolf. El Imperio Chino. México, España, Argentina: Siglo XXI, 1973.

FÜLÖP-MILLER, René. Os santos que abalaram o mundo. $16^{\circ}$ edição, Rio de Janeiro: José Olympio, 2004.

GERNET, Jacques, O Mundo Chinês - Uma Civilização e uma História. Lisboa - Rio de Janeiro: Edições Cosmos. Volume I, 1974.

O Mundo Chinês. Lisboa-Rio de Janeiro: Edições Cosmos. Volume II, 1975.

GOMES, Luís Gonzaga. Macau. Um Município com História. Macau: Leal Senado de Macau,

${ }^{54}$ BROCKEY, Matthew Liam. Journey to the East. Op. cit., p. 200. 
1997.

GOODRICH. L.C. Historia del Pueblo Chino. México, Buenos Aires: Fondo de Cultura Económica, 1950.

GRANET, Marcel. O Pensamento Chinês. 2 ed., Rio de Janeiro: Contraponto, 2004.

HINNELLS, John R. O Dicionário das Religiões. 10 ed., São Paulo: Editora Cultrix, 1984.

JIMÉNEZ, José Antonio Cervera. "La Interpretación Ricciana del Confucianismo". In Estudios de Asia y África, Cidade do México, vol. XXXVII, n. 2, mayo-agosto. 2002 p. 211 239. Disponível em: $<$ http://www.redalyc.org/pdf/586/58637201.pdf $>$ Acessado em: 29/11/2017.

LUIZETTO, Flávio. Reformas Religiosas. 4 ed., São Paulo: Contexto, 1998.

MAGALHÃES, Gabriel de. Nova Relação da China. Macau: Fundação Macau, 1997.

MESQUITELA, Gonçalo. História de Macau. Instituto Cultural de Macau, 1996, v. I, t. I.

História de Macau. Instituto cultural de Macau. v. I, t. II, 1996.

MULLET, Michel. A Contra - Reforma e a Reforma Católica nos Princípios da Idade Moderna Européia. Lisboa: Gradiva, 1984.

RAMOS, João de Deus. História das Relações Diplomáticas entre Portugal e a China. O Padre Antônio Magalhães, S. J., e a Embaixada de Kangxi a D. João V (1721-1725). Macau: Instituto Cultural de Macau, 1991.

RICCI, Matthew. China in the Sixteenth Century: The Journals of Matthew Ricci : 15831610. New York: Random House, 1953.

RODRIGUES, Francisco. Jesuítas Portugueses - Astrônomos na China (1583-1805). Instituto Cultural de Macau, 1990.

RONAN, Charles E. S. J; OH, Bonnie B. C. East Meets West: The Jesuit Mission in China, 1582-1773. Chicago: Loyola University Press. 1988.

SEMEDO, Pe. Álvaro S. J. Relação da Grande Monarquia da China. Direcção dos Serviços de Educação e Juventude/Fundação Macau , 1994.

SPENCE, Jonathan D. Em Busca da China Moderna.Quatro Séculos de História. São Paulo: Companhia das Letras, 1995.

O Palácio da Memória de Matteo Ricci. A História de uma Viagem: Da Europa da Contra - Reforma à China da Dinastia Ming. São Paulo: Companhia das Letras, 1986.

XAVIER, Francisco. Cartas e Escritos de São Francisco Xavier. São Paulo: Edições Loyola, 1996.

YONGZHENG, Imperador. Ampliação do Santo Decreto. Macau: Fundação Macau,1995. 